\title{
Signs of the End of the Paradox? Cohort Shifts in Smoking and Obesity and the Hispanic Life Expectancy Advantage
}

\author{
Jennifer Van Hook, Michelle L. Frisco, Carlyn E. Graham
}

The Pennsylvania State University

Abstract: Hispanics' paradoxical life expectancy advantage over whites has largely been attributed to Hispanics' lower smoking prevalence. Yet across birth cohorts, smoking prevalence has declined for whites and Hispanics, and Hispanics' obesity prevalence has increased substantially. Our analysis uses data from the 1989 to 2014 National Health Interview Survey and Linked Mortality files to investigate whether these trends could lead Hispanics to lose their comparative mortality advantage. Simulations suggest that foreign-born Hispanics' life expectancy advantage over whites is likely to persist because cohort trends in smoking and obesity largely offset each other. However, U.S.born Hispanics' life expectancy advantage over whites is likely to diminish or disappear entirely as the 1970s and 1980s birth cohorts age due to increases in obesity prevalence and the relatively high mortality risks of those who are obese. Results have important implications for understanding the future of immigrants' health advantages and ethnic disparities in health.

Keywords: Hispanic paradox; life expectancy; mortality; obesity; smoking; cohort trends

Citation: Van Hook, Jennifer, Michelle L. Frisco, and Carlyn E. Graham. 2020. "Signs of the End of the Paradox? Cohort Shifts in Smoking and Obesity and the Hispanic Life Expectancy Advantage." Sociological Science 7: 391-414.

Received: June 13, 2020

Accepted: July 20, 2020

Published: August 31, 2020

Editor(s): Jesper Sørensen, Sarah Soule

DOI: 10.15195/v7.a16

Copyright: (C) 2020 The Author(s). This open-access article has been published under a Creative Commons Attribution License, which allows unrestricted use, distribution and reproduction, in any form, as long as the original author and source have been credited. (0)(1)
$\mathrm{D}$ ESPITE their relatively low socioeconomic status (Morales et al. 2002), Hispanics have a well-documented life expectancy advantage over non-Hispanic whites (hereafter, "whites") that is particularly large among the foreign-born (Lariscy, Hummer, and Hayward 2015; Hummer et al. 1999; Hummer et al. 2000; Markides and Coreil 1986). Given the important role of socioeconomic status for health and longevity (Adler and Newman 2002; Frytak, Harley, and Finch 2003; Hayward and Gorman 2004) and evidence suggesting that Hispanics' life expectancy advantage is unlikely to be a data artifact (Hummer et al. 2007; Turra and Elo 2008), their longevity edge has been deemed a "Hispanic paradox."

Nevertheless, researchers speculate that the life expectancy advantage of Hispanics could be eroding because of two counteracting trends. First, Hispanics' advantage is largely attributable to their historically lower smoking prevalence relative to whites, especially among the foreign-born (Fenelon 2013; Lariscy, Hummer, and Hayward 2015). Yet smoking prevalence has declined rapidly since the mid-1960s, leading some to speculate that Hispanic immigrants' life expectancy advantage could shrink (Bostean, Ro, and Fleischer 2017). Second, obesity prevalence has been increasing, and Hispanics are now one of the heaviest racial/ethnic groups in the United States. This is particularly evident among young adults and the U.S.born (Akresh 2008; Barcenas et al. 2007; Kaplan et al. 2004; McTigue, Garrett, and Popkin 2002). Accordingly, Goldman (2016) asks whether Hispanics' vulnerability to a host of health problems related to obesity, including diabetes, disability, and inflammation, could begin to counteract their life expectancy advantages. 
To our knowledge, research to date has only theorized about, but has not yet tested, whether offsetting smoking and obesity trends may change the shape of the Hispanic paradox. In this study, we make this contribution using an innovative methodological approach. We investigate whether declines in smoking on the one hand and increasing obesity prevalence on the other may erode Hispanics' life expectancy advantage over whites. Our research is central for understanding whether the largest ethnic minority group in the country could face declining longevity in the years to come. Study findings are also an important barometer of prospective U.S. health disparities and resulting health care burdens that they will produce.

We analyze data from multiple sources to simulate how life expectancy at age 35 is likely to change because of changes in the prevalence of early adult smoking and obesity across birth cohorts born in the late 1920s through the mid-1980s. We focus on early adult behavior for two reasons. First, when these health risks emerge by early adulthood, there is a greater likelihood of lifelong persistent, cumulative health disadvantage (Clarke et al. 2010; Freedman et al. 2001) and, in turn, reduced life expectancy (Peeters et al. 2003). Additionally, measuring smoking and obesity in young adulthood reduces the problems of mortality selection and reverse causality. Smokers and obese individuals represent a smaller share of survivors at older ages, and people tend to lose weight or quit smoking during the physical decline leading to death (Reither, Olshansky, and Yang 2011).

Throughout the analysis, we distinguish between U.S.-born and foreign-born Hispanics. Changes in the life expectancy of these two groups may not be uniform because the foreign-born are positively selected into the United States on health (Riosmena, Kuhn, and Jochem 2017), whereas the U.S.-born have earlier and longer exposures to unhealthy U.S. norms and behavior (Antecol and Bedard 2006; Hamilton, Palermo, and Green 2015). In the next section, we elaborate on factors that may contribute to nativity differences in the prevalence of smoking and obesity and the mortality risks associated with these health conditions.

\section{Background}

Trends in smoking and obesity have changed significantly over the last 50 years. In 1965, nearly half of all U.S. adults smoked, but by 2016, this percentage had fallen to 15.5 percent (Centers for Disease Control and Prevention 2016a, 2016b). Smoking tends to start and become an established habit early in life. Nearly 90 percent of adult smokers began to smoke before age 18, and 98 percent first tried smoking before age 26 (U.S. Department of Health and Human Services 2014). Therefore, changes in U.S. smoking behaviors have occurred largely through cohort replacement. Men born in the early 20th century through the 1950s, and women born in the 1920s through the 1950s, had a particularly high smoking prevalence and smoking-related morbidity and mortality, but later-born cohorts are much less likely to have ever smoked and therefore have been much less likely to suffer from smoking-related diseases such as lung cancer (Preston and Wang 2006).

During this same time period, trends in obesity have gone in the opposite direction. The obesity prevalence of both men and women was relatively flat and 
low up until the mid-1970s. At that time, 10 percent of men and 15 percent of women were obese (Fryar, Carroll, and Ogden 2016). Since then, the obesity prevalence has skyrocketed, with the most recent estimates suggesting that 43 percent of men and 41 percent of women are currently obese (Hales et al. 2020). These changes appear to have occurred through both cohort replacement and period changes that impacted all cohorts (Kranjac and Wagmiller 2019; Reither, Hauser, and Yang 2009). Early adulthood is a particularly critical life course stage when weight gain and obesity development are common, most likely because of the number of life course transitions young adults undergo (Dietz 2017). Moreover, it is rare for adults to lose and keep off substantial amounts of body weight (Van Baak and Mariman 2019; Weiss et al. 2007) unless it is the result of muscle loss that is part of aging after midlife (Kim, Kim, and Won 2018) or serious illness (Gaddey and Holder 2014), often near the very end of life (Alley et al. 2010).

Prior research on the entire U.S. population suggests that offsetting trends in smoking and obesity have cancelled each other out, leading to minimal net changes in life expectancy, particularly among women (Preston et al. 2014). Yet in the future, smoking is likely to remain an important cause of death and excess mortality, whereas obesity is increasingly becoming another important mortality risk (Preston et al. 2014; Stewart, Cutler, and Rosen 2009).

Research to date has not investigated whether these changes in smoking and obesity prevalence will reshape the Hispanic paradox. In a study that used lung cancer-related deaths to approximate the impact of smoking on life expectancy, smoking was tied to a widening of the Hispanic life expectancy advantage at age 50 relative to whites from 1990 to 2010 (Fenelon and Blue 2015). However, this study focused on older adults born in 1960 or earlier, so it may not have fully captured declines in smoking observed among more recent cohorts of young adults. Another recent study that disaggregated Hispanics by nativity suggests that the elimination of smoking and obesity would erode the life expectancy advantage of U.S.-born Hispanics over whites but that the advantage of Hispanic immigrants would persist (Frisco, Van Hook, and Hummer 2019). Yet this study simulated a "best-case scenario" in which these health risks are eliminated altogether. These lofty public health goals are laudable but unlikely to be realized in the United States any time soon.

We build on the prior work just cited to estimate cohort changes in life expectancy disparities between Hispanics and whites across birth cohorts that are attributable to observed cohort compositional changes in smoking and body weight in early adulthood. It is difficult to develop a priori research expectations about these potential changes. This is because prior research has not specifically estimated whether Hispanic-white gaps in smoking and obesity across birth cohorts are narrowing or widening. Therefore, we examined these trends in our study sample (described below) in order to develop research expectations.

Our systematic analysis of the 1989 to 2014 National Health Interview Survey suggests that ethnic/nativity gaps in both smoking and obesity have widened (the data and measures are described below). Figure 1 shows the percentage of adults who had smoked for at least five years by age 25 across 10-year birth cohorts for each gender and ethnic/nativity group. We focus on smoking for at least five 

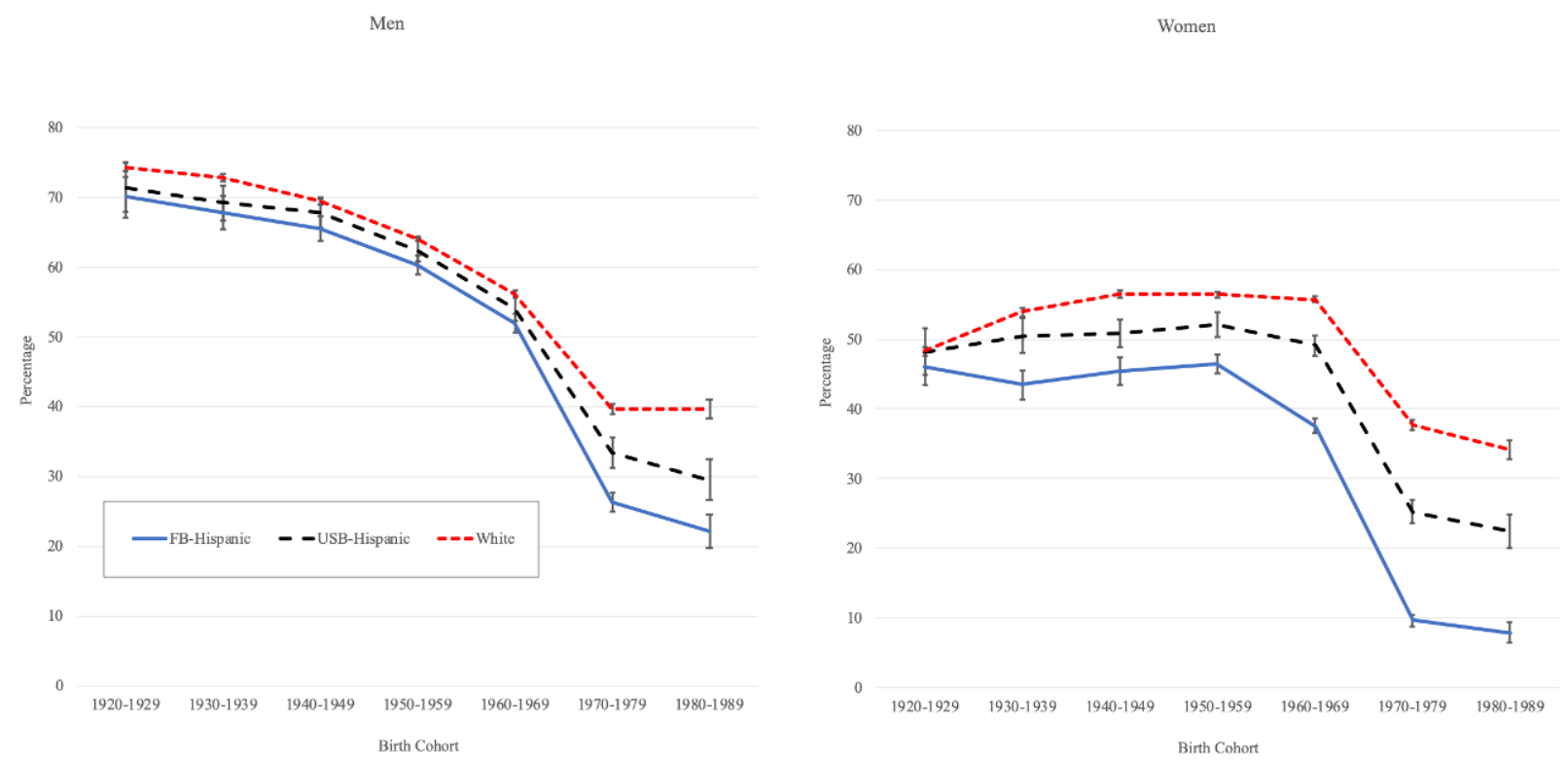

Figure 1: Percentage smoked for five or more years by age 25 by birth cohort, ethnicity/nativity, and gender. Source: 1989 to 2014 National Health Interview Survey and 1999 to 2014 National Health and Nutrition Examination Survey. FB, foreign-born; USB, U.S.-born.

years to eliminate those who only smoked briefly as young adults. ${ }^{1}$ Among men, ethnic/nativity differences are relatively small among birth cohorts born before the 1970s, but differences widen and become statistically significant among the 1970s and 1980s birth cohorts, with foreign-born Hispanics smoking the least often, U.S.-born Hispanics smoking more, and whites smoking the most. We see a similar pattern for women, except that statistically significant gaps between the three ethnic/nativity groups are evident across all but the earliest-born cohorts. Thus, even though smoking prevalence has declined for all groups, a Hispanic advantage in smoking has emerged among men and has widened among women, particularly among foreign-born Hispanics who smoke less than U.S.-born Hispanics and whites.

Whereas smoking declined in prevalence, obesity in early adulthood (i.e., having a body mass index [BMI] of 30 or greater) increased dramatically across cohorts for both men and women and for all ethnic/nativity groups, particularly for those born in the 1970s and 1980s (Figure 2). The rise in obesity was especially pronounced among U.S.-born Hispanics, increasing fourfold from the earliest- to the latest-born cohorts among both men and women. Even more troubling is that the share of U.S.-born Hispanics who are class 2 obese (having a BMI of 35 or higher) increased more than tenfold (from one percent to 13 percent among men and from one percent to 15 percent among women; results shown in Figure B2 of the online supplement). The gap in the obesity prevalence of this group relative to whites and foreign-born Hispanics also grew substantially over time. In contrast, the gaps between foreign- 

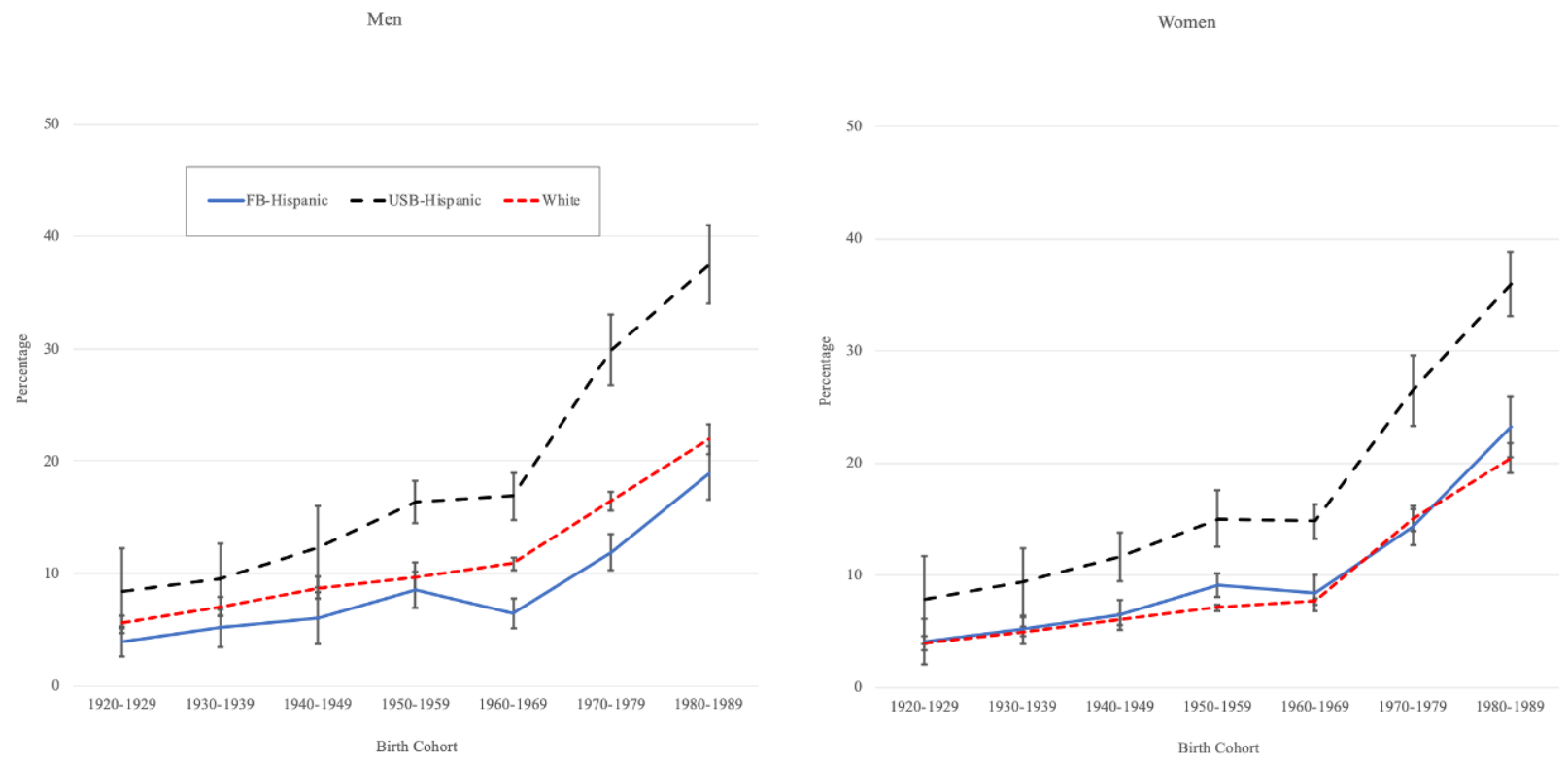

Figure 2: Percentage obese (BMI $\geq 30$ ) at age 25 by birth cohort, ethnicity/nativity, and gender. Source: 1989 to 2014 National Health Interview Survey and 1999 to 2014 National Health and Nutrition Examination Survey. FB, foreign-born; USB, U.S.-born.

born Hispanics and whites among both men and women were much smaller and statistically insignificant for nearly all birth cohorts.

By just considering the changing cohort trends in smoking and obesity, it appears as if foreign-born Hispanics could retain their life expectancy advantage. They tend to smoke less than whites, and this advantage has been growing among later-born cohorts. Additionally, trends in obesity prevalence between these two groups are quite similar. In contrast, the respective advantages and disadvantages of smoking and obesity prevalence among U.S.-born Hispanics calls into question whether they will retain a life expectancy advantage.

Yet this is before accounting for the magnitude of the mortality risk of smoking and obesity. All things being equal, changes in the prevalence of health behaviors with greater mortality risks will impact life expectancy more than changes in less risky health behaviors. For this reason, it is important to account for the duration of smoking and severity of obesity, as longer durations spent smoking and higher body mass index scores tend to pose greater risks (Flanders et al. 2003; Freedman et al. 2006). Likewise, it is important to account for the possibility that the mortality risks of smoking and obesity vary across groups. Limited access to health care, greater susceptibility to comorbidities, and greater intensity or severity of smoking or obesity could intensify the mortality risks of these conditions. If the association of smoking or obesity with mortality is stronger for one group than another, then an equal-sized decline in smoking (or increase in obesity prevalence) would boost (or reduce) life expectancy more for the group with the larger hazard ratio. Mortality risks of smoking may be weaker among Hispanics, particularly foreign-born 
Hispanics, than among non-Hispanic whites because Hispanic smokers smoke less intensively and for shorter periods of time than do white smokers (Siahpush et al. 2010; Trinidad et al. 2009). Conversely, Hispanics appear to be quite vulnerable to comorbidities related to obesity, such as diabetes (Zhang and Rodriguez-Monguio 2012), which could increase their mortality risks associated with obesity.

These studies, along with our cohort analyses of early adult smoking and obesity prevalence, solidify the notion that the paradoxical life expectancy advantage of Hispanics may not be maintained evenly among foreign-born and U.S.-born Hispanics. We expect the Hispanic paradox to be maintained or even amplified across birth cohorts for foreign-born Hispanics because their health behaviors did not worsen relative to whites. Instead, their smoking prevalence declined more than among whites, and their obesity prevalence increased by about the same amount. However, we expect the Hispanic paradox to diminish for U.S.-born Hispanics. Not only are they becoming one of the heaviest ethnic/nativity groups in the United States, obesity may also be more strongly related to mortality for this group given their high risk of obesity-related comorbidities.

\section{Methods}

To investigate the research expectations just discussed, we produce counterfactual life expectancies at age 35 for U.S.-born whites, U.S.-born Hispanics, and foreignborn Hispanics had they smoked the same duration and had a similar body weight composition in early adulthood as their co-ethnics in various birth cohorts ranging from those born in the 1920s to those born in the 1980s, while holding other factors constant. We employ detailed smoking and weight status categories to account for the severity of these health conditions and allow for mortality risks to vary across ethnicity/nativity groups and by gender. Below, we outline the data sources, measures, and methods used to carry out this analysis.

\section{Data Sources}

We leverage multiple sources of data. Our primary data source is the 1989 to 2014 National Health Interview Survey (NHIS) (Blewett et al. 2019). Advantages of the NHIS include its large sample; continuous data collection over several decades; selfreported measures of height, weight and smoking history; and its mortality followup. One limitation of the NHIS, however, is that it does not include retrospective information about body weight in early adulthood. To help overcome this limitation we supplemented NHIS data with the 1999 to 2014 National Health and Nutrition Examination Survey (NHANES). The NHANES sample is too small to support our analyses, but a key advantage is that it includes retrospective self-reports of height and weight at age 25. We combine the NHIS with the NHANES using crosssample multiple imputation (CSMI). This technique imputes data on retrospective weight and height for observations in the NHIS based on information available in NHANES. CSMI has been used in prior research to increase statistical power (Rendall et al. 2013; Van Hook et al. 2015; Baker, Rendall, and Weden 2015) and has been shown to yield unbiased estimates under certain assumptions that we 
meet. A full description of the CSMI methodology, including details that will allow for replication of our work and supplementary analysis validating that we meet the assumptions of the methodology, is available in Appendix A of the online supplement.

Our use of the CSMI methodology is an important innovation that gives us the statistical power needed to examine smoking and weight status in early adulthood for detailed demographic groups by ethnicity/nativity, gender, and birth cohort and to account for group-specific mortality risks. This innovation sharpens our focus on these fine-grained patterns, thus permitting us to significantly advance research on the likely durability of the Hispanic paradox over time.

Another NHIS limitation is that, despite its large sample size, it is still too small to support the construction of life tables by health conditions, ethnicity/nativity, and gender. Therefore, we calibrated our mortality estimates so that they were consistent with 2012 National Center for Health Statistics (NCHS) life tables for Hispanic and non-Hispanic white men and women. Specifically, we combined estimates of the relative mortality risks of smoking and weight status in young adulthood, based on hazard models estimated using the NHIS data, with 2012 life tables published by NCHS. We used this procedure, as described in more detail in the next section, to produce detailed estimates of age-specific mortality rates by smoking and weight status in early adulthood, ethnicity/nativity, and gender. Because of the way the estimates were calibrated, these detailed estimates were consistent with NCHS life table estimates when aggregated up to the level of ethnic/nativity and gender groups. ${ }^{2}$

\section{Samples}

We restricted our NHIS and NHANES samples to U.S.-born white, U.S.-born Hispanic, and foreign-born Hispanic adults aged 25 to 84 at interview who were born in 1920 or later and were eligible for the mortality follow-up. We excluded those in the top-coded $85+$ category due to imprecise information on age. The NHIS sample included 728,700 adults (69,010 foreign-born Hispanics, 45,359 U.S.-born Hispanics, and 614,331 whites). Of these, 134,705 died during follow-up (7,884 foreign-born Hispanics, 6,117 U.S.-born Hispanics, and 120,654 whites). The NHANES sample included 11,228 adults (2,252 foreign-born Hispanics, 1,322 U.S.-born Hispanics, and 7,654 whites). Of these, 2,753 died during follow-up (370 foreign-born Hispanics, 315 U.S.-born Hispanics, and 2,068 whites).

\section{Measures}

Sample descriptive statistics for all analytic variables are shown in Table 1. Our estimates of life expectancy were partially based on models predicting the hazard of death. The key dependent variable in these models was whether the person died during the follow-up period after the interview but before January 1, 2014, and age at death among decedents. Vital status and age at death, measured to the nearest quarter year, were obtained from the linked death certificate data. As shown in Table 1, foreign-born and U.S.-born Hispanics were significantly less likely to die 
Table 1: Sample descriptives (weighted mean or percentage), by gender and ethnicity/nativity.

\begin{tabular}{|c|c|c|c|c|c|c|}
\hline & \multicolumn{3}{|c|}{ Men } & \multicolumn{3}{|c|}{ Women } \\
\hline & FB & USB & USB & FB & USB & USB \\
\hline & Hispanic & Hispanic & White & Hispanic & Hispanic & White \\
\hline Died during follow-up period (\%) & $12.7^{*}$ & $14.7^{*}$ & 19.7 & $9.1^{*}$ & $10.4^{*}$ & 16.3 \\
\hline \multicolumn{7}{|l|}{ Duration smoked by age $25(\%)$} \\
\hline Never smoked & $41.8^{*}$ & $35.3^{*}$ & 28.3 & $59.9^{*}$ & $47.6^{*}$ & 37.6 \\
\hline Less than five years & $7.0^{*}$ & $9.8^{*}$ & 8.8 & $4.5^{*}$ & $7.9^{*}$ & 9.3 \\
\hline Five to nine years & $37.3^{*}$ & $41.1^{*}$ & 44.8 & $32.6^{*}$ & $37.2^{*}$ & 44.1 \\
\hline $10+$ years & $13.9^{*}$ & $13.8^{*}$ & 18.1 & $3.0^{*}$ & $7.3^{*}$ & 9.0 \\
\hline \multicolumn{7}{|l|}{ Weight status at age 25 (\%) } \\
\hline $\mathrm{BMI}<25$ & 53.9 & $46.2^{*}$ & 54.3 & $61.0^{*}$ & $55.2^{*}$ & 70.4 \\
\hline BMI = 25-29 (overweight) & $37.7^{*}$ & 35.1 & 35.8 & $29.5^{*}$ & $27.8^{*}$ & 22.2 \\
\hline $\mathrm{BMI}=30-34($ class 1 obese $)$ & $7.6^{*}$ & $14.7^{*}$ & 8.8 & $8.1^{*}$ & $12.4^{*}$ & 6.0 \\
\hline $\mathrm{BMI}=35+($ class 2 obese $)$ & $0.8^{*}$ & $4.0^{*}$ & 1.1 & 1.4 & $4.6^{*}$ & 1.4 \\
\hline Age at interview & $42.7^{*}$ & $42.5^{*}$ & 47.8 & $44.3^{*}$ & $43.0^{*}$ & 49.2 \\
\hline Year of interview & $2001^{*}$ & $2001^{*}$ & 1999 & $2001^{*}$ & $2001^{*}$ & 2000 \\
\hline \multicolumn{7}{|l|}{ Education (\%) } \\
\hline Less than ninth grade & $35.0^{*}$ & $8.2^{*}$ & 4.3 & $33.9^{*}$ & $10.0^{*}$ & 3.6 \\
\hline Ninth to 11th grade & $14.2^{*}$ & $11.9^{*}$ & 7.4 & $13.7^{*}$ & $13.4^{*}$ & 7.5 \\
\hline 12th grade & $25.0^{*}$ & $34.2^{*}$ & 32.8 & $25.3^{*}$ & $33.4^{*}$ & 35.7 \\
\hline Some postsecondary & $14.1^{*}$ & $28.4^{*}$ & 24.2 & $15.6^{*}$ & $27.9^{*}$ & 26.5 \\
\hline College graduate & $11.7^{*}$ & $17.3^{*}$ & 31.3 & $11.5^{*}$ & $15.3^{*}$ & 26.6 \\
\hline \multicolumn{7}{|l|}{ Birth cohort $(\%)$} \\
\hline 1920-1929 & $3.7^{*}$ & $5.0^{*}$ & 9.8 & $4.9^{*}$ & $5.8^{*}$ & 12.1 \\
\hline 1930-1939 & $7.6^{*}$ & $8.4^{*}$ & 12.9 & $9.4^{*}$ & $8.7^{*}$ & 14.0 \\
\hline 1940-1949 & $13.3^{*}$ & $12.9^{*}$ & 19.2 & $14.7^{*}$ & $12.6^{*}$ & 18.8 \\
\hline 1950-1959 & $22.1^{*}$ & $22.8^{*}$ & 25.1 & $22.3^{*}$ & $22.8^{*}$ & 23.7 \\
\hline 1960-1969 & $29.4^{*}$ & $28.2^{*}$ & 21.7 & $27.0^{*}$ & $27.1^{*}$ & 20.4 \\
\hline 1970-1979 & $18.0^{*}$ & $14.8^{*}$ & 8.3 & $16.4^{*}$ & $15.6^{*}$ & 8.1 \\
\hline 1980-1989 & $5.8^{*}$ & $7.8^{*}$ & 3.0 & $5.3^{*}$ & $7.5^{*}$ & 2.9 \\
\hline Unweighted $N$ & 31,777 & 20,101 & 292,086 & 37,233 & 25,258 & 322,245 \\
\hline Unweighted number of deaths & 4,347 & 3,354 & 63,624 & 3,537 & 2,813 & 57,030 \\
\hline
\end{tabular}

Notes: Sample is 1989 to 2014 National Health Interview Survey with Mortality Linkages and 1999 to 2014 National Health and Nutrition Examination Survey with Mortality Linkages. Sample restricted to adults aged 25 to 84 at interview who were eligible for mortality follow-up. FB, foreign-born; USB, U.S.-born.

$* p<0.05$ (significantly different from whites; comparisons made within gender).

during follow-up than U.S.-born whites, which may be due to Hispanics' younger average ages and/or lower mortality rates.

The first key independent variable is smoking status in early adulthood. This variable indicates whether respondents ever smoked before the age of 25 , and if so, the number of years they smoked as of age 25 (zero to four, five to nine, and 10 or more years). This measure was constructed from NHIS survey questions about the ages at which the respondent started and stopped smoking. We wanted to distinguish between respondents who may have temporarily experimented with smoking but gave it up (i.e., those who smoked less than five years) versus those 
who started early and maintained the habit (those who smoked five to nine or 10 or more years). As shown in Table 1, men generally smoked more than women, and white men and women are significantly more likely than all Hispanic men and women regardless of nativity to report that they smoked for five to nine or 10+ years at age 25 .

The second key independent variable was weight status at age 25 , based on self-reports of height and weight at age 25 that we corrected for self-report bias (see Appendix A of the online supplement for details). We classified weight status using categories recommended by the CDC: ${ }^{3}$ having a BMI less than 25 (normal weight), 25 to 29 (overweight), 30 to 34 (class 1 obese), and 35+ (class 2 obese). Appendix A of the online supplement explains how we imputed weight and height at age 25 for NHIS respondents using CSMI procedures following guidelines outlined by Rendall and colleagues (2013).

In some analyses, we examined the combined impact of both smoking and weight status in early adulthood. We did this to account for correlations between smoking- and weight-related behaviors and for the possibility that mortality risks due to smoking and obesity may compound. We distinguished among the following six categories: (1) not obese (BMI <30) and never smoked, (2) not obese and smoked less than five years, (3) not obese and smoked five or more years, (4) obese (BMI $\geq 30$ ) and never smoked, (5) obese and smoked less than five years, and (6) obese and smoked five or more years.

Additional measures in the analysis include age at interview, sex, and educational attainment. We also account for Hispanic ethnicity and foreign place of birth. Individuals were classified as U.S.-born white, U.S.-born Hispanic, or foreign-born Hispanic. Foreign-born Hispanic men and women are the youngest and least educated of the three groups, whereas U.S.-born white men and women are the oldest and most educated (Table 1).

\section{Estimating Changes in Life Expectancy Due to Cohort Changes in Smoking and Weight}

In this section, we show how life expectancy is mathematically related to a group's weight status and smoking composition, and how it would change if it had a different weight status or smoking composition.

Life expectancy is an estimate of average length of life for a synthetic cohort that experiences the complete set of conditional probabilities of dying $\left(q_{x}\right)$ across the lifespan. Life expectancy is related to weight and smoking because the probabilities of dying (the $q_{x}$ 's) vary by smoking and weight status. Taking weight status as an example, each of the $q_{x}$ 's can be expressed as the sum of weight-specific $q_{x}$ 's for those in each of the four weight status categories $\left(w_{1}\right.$ through $\left.w_{4}\right)$, weighted by the proportions in each of the weight categories $\left(p_{x, w 1}\right.$ through $\left.p_{x, w 4}\right)$ :

$$
q_{x}=q_{x, w 1} p_{x, w 1}+q_{x, w 2} p_{x, w 2}+q_{x, w 3} p_{x, w 3}+q_{x, w 4} p_{x, w 4}
$$

Assuming the risk of death is greater for those who are in the heavier weight categories, Equation (1) shows how a group's overall $q_{x}$ value would increase if the share of people in the heavier categories were to increase. Parallel equations 
can be expressed in terms of the four smoking status categories and the six weightsmoking status categories.

We first estimated values for Equation (1) for each ethnicity/nativity group by sex. We used NHIS data to calculate the age-specific proportions in each weight, smoking, and weight-smoking combination category for each group by sex (the " $p$ " terms in Eq. [1]). To estimate the mortality probabilities (the " $q_{x}$ " terms on the righthand side of the equation), we used NHIS data to estimate Cox proportional hazard models predicting the hazard of dying as a function of weight status and smoking status while controlling for age at interview, year of interview, and education. We also estimated a second set of models that use the combined weight-smoking variable as a predictor. The models were estimated separately by sex and ethnicity / nativity ${ }^{4}$ and were weighted and adjusted to account for the stratified, clustered NHIS sample design. ${ }^{5}$ We then multiplied the hazard ratios, which were expressed as ratios relative to the sample average, by the NCHS-published $q_{x}{ }^{\prime} \mathrm{s}\left(q_{x, \mathrm{NCHS}}\right)$, to obtain estimates of the weight-, smoking-, and weight-smoking-specific $q_{x}{ }^{\prime}$ s by ethnicity/nativity and sex. ${ }^{6}$ Multiplying the hazard ratios by the NCHS estimates ensured that the weight- and smoking-specific estimates, when averaged across categories, matched the NCHS estimates for all weight and smoking categories combined.

After estimating values for Equation (1), we estimated life expectancy from the estimated $q_{x}$ 's for each ethnicity/nativity group by sex. To estimate counterfactual $q_{x}$ 's and life expectancies, we changed the $p_{x}$ values to reflect changes in weight, smoking, and weight and smoking composition across different birth cohorts.

Finally, we bootstrapped estimates of standard errors of observed and simulated estimates of life expectancy across 500 iterations.

\section{Results}

\section{Differential Mortality Risks}

We first examine how mortality risks related to smoking and weight status have changed across cohorts for Hispanics and whites. As already discussed, smoking prevalence at age 25 (i.e., having smoked at least five years) declined more rapidly across birth cohorts among Hispanics, especially foreign-born Hispanics, than whites (Figure 1). At the same time, obesity prevalence in young adulthood increased more among U.S.-born Hispanics than foreign-born Hispanics and whites (Figure 2). Especially notable is the rapid increase in class 2 obesity among U.S.-born Hispanics (Figure B2 of the online supplement).

The impact of these changes on life expectancy depends on the degree to which these health risks elevate mortality risk. Prior literature led us to hypothesize that mortality risks would be weaker among Hispanics than whites in the case of smoking, but stronger for Hispanics in the case of obesity. Indeed, these expectations were borne out in our analyses of the NHIS data. We estimated Cox proportional hazards models predicting mortality. After finding significant interactions between weight status, smoking and ethnicity/nativity, we estimated separate models by gender and ethnicity/nativity. Results are shown in Table 2. 
Table 2: Cox proportional hazards models predicting mortality (hazard ratios).

\begin{tabular}{|c|c|c|c|c|c|c|}
\hline & \multicolumn{3}{|c|}{ Men } & \multicolumn{3}{|c|}{ Women } \\
\hline & $\begin{array}{c}\text { FB } \\
\text { Hispanic }\end{array}$ & $\begin{array}{c}\text { USB } \\
\text { Hispanic }\end{array}$ & $\begin{array}{l}\text { USB } \\
\text { White }\end{array}$ & $\begin{array}{c}\text { FB } \\
\text { Hispanic }\end{array}$ & $\begin{array}{c}\text { USB } \\
\text { Hispanic }\end{array}$ & $\begin{array}{l}\text { USB } \\
\text { White }\end{array}$ \\
\hline \multicolumn{7}{|c|}{$\begin{array}{l}\text { Duration smoked by age } 25 \text { (ref }=\text { never } \\
\text { smoked) }\end{array}$} \\
\hline Less than five years & $1.24^{*}$ & 1.14 & $1.33^{+}$ & 1.04 & $1.29^{w \dagger}$ & $1.43^{*}$ \\
\hline Five to nine years & $1.17^{w \dagger}$ & $1.23^{w \dagger}$ & $1.48^{+}$ & $1.05^{w}$ & $1.27^{w+}$ & $1.50^{*}$ \\
\hline $10+$ years & $1.28^{w \dagger}$ & $1.36^{w \dagger}$ & $1.72^{+}$ & $1.16^{w}$ & $1.52^{w+}$ & $1.86^{*}$ \\
\hline \multicolumn{7}{|c|}{ Weight status at age 25 (ref: $\mathrm{BMI}<25$ ) } \\
\hline BMI = 25-29 (overweight) & $1.25^{*}$ & $1.50^{w \dagger}$ & $1.25^{*}$ & $1.36^{*}$ & $1.54^{*}$ & $1.46^{*}$ \\
\hline $\mathrm{BMI}=30-34($ class 1 obese $)$ & $1.58^{*}$ & $2.10^{w \dagger}$ & $1.59^{+}$ & $1.71^{*}$ & $1.99^{*}$ & $1.93^{*}$ \\
\hline $\mathrm{BMI}=35+($ class 2 obese $)$ & 1.64 & $2.84^{w \dagger}$ & $2.37^{+}$ & $2.27^{+}$ & $3.02^{+}$ & $2.69^{*}$ \\
\hline
\end{tabular}

Notes: Sample is 1989 to 2014 National Health Interview Survey with Mortality Linkages and 1999 to 2014 National Health and Nutrition Examination Survey with Mortality Linkages. Sample restricted to adults aged 25 to 84 at interview who were eligible for mortality follow-up. All models control for age at interview, year, and education. FB, foreign-born; USB, U.S.-born. $+p<0.01 ; * p<0.05 ;{ }^{w}$, significantly different from whites in interactive model $(p<0.05)$.

As expected, longer durations of smoking and heavier weight categories at age 25 were associated with significantly greater mortality hazards, albeit with a few exceptions that were likely due to low statistical power. More to the point, the hazards related to smoking more than five years among both men and women were significantly weaker for foreign-born and U.S-born Hispanics than whites, as denoted by the " $w$ " superscripts. ${ }^{7}$ This means that the sharp reductions in smoking prevalence may not extend Hispanics' life expectancy as much as for whites, potentially leading to whites catching up with Hispanics in life expectancy. Additionally, hazards associated with overweight, class 1 obesity, and class 2 obesity were significantly stronger for U.S.-born Hispanic men than white men. Thus, the recent increases in obesity seen for U.S.-born Hispanic men may take an especially large toll on their life expectancy, which could reduce this group's mortality advantage.

\section{Cohort Shifts in Life Expectancy}

We next assess the degree to which cohort changes in early adult smoking and weight status are altering life expectancies across ethnicity/nativity groups and reshaping the Hispanic mortality paradox. Table 3 presents actual and simulated life expectancies by ethnicity/nativity among men and women. The first row of results shows actual life expectancy at age 35 in 2012, which is highest among foreign-born Hispanics, lower for U.S.-born Hispanics, and lowest for whites among both men and women. These findings are well established in demographic and epidemiological research.

The next three panels present simulated life expectancies when each ethnic/nativity group is given the smoking duration composition, weight composition, and both the smoking duration and weight composition of their earliest (1920s) and latest 
Table 3: Simulated change in life expectancy at age 35 due to cohort compositional change in smoking duration and weight status.

\begin{tabular}{|c|c|c|c|c|c|c|}
\hline & \multicolumn{3}{|c|}{ Men } & \multicolumn{3}{|c|}{ Women } \\
\hline & $\begin{array}{c}\text { FB } \\
\text { Hispanic }\end{array}$ & $\begin{array}{c}\text { USB } \\
\text { Hispanic }\end{array}$ & $\begin{array}{l}\text { USB } \\
\text { White }\end{array}$ & $\begin{array}{c}\text { FB } \\
\text { Hispanic }\end{array}$ & $\begin{array}{c}\text { USB } \\
\text { Hispanic }\end{array}$ & $\begin{array}{l}\text { USB } \\
\text { White }\end{array}$ \\
\hline $\begin{array}{l}\text { Panel 1. Life expectancy at age } 35 \text { in } \\
2012 \\
\text { Panel 2. If given smoking composi- } \\
\text { tion of: }\end{array}$ & 46.3 & 45.0 & 43.3 & 51.1 & 49.1 & 47.3 \\
\hline 1920-1929 birth cohorts & 46.1 & 44.8 & 43.0 & 51.0 & 48.7 & 47.1 \\
\hline 1980-1989 birth cohorts & 46.9 & 45.6 & 44.3 & 51.1 & 49.1 & 47.3 \\
\hline Change & $0.8^{+}$ & $0.9^{\dagger}$ & $1.3^{+}$ & 0.1 & $0.4^{+}$ & $0.2^{+}$ \\
\hline $\begin{array}{l}\text { Panel 3. If given weight composition } \\
\text { of: }\end{array}$ & & & & & & \\
\hline 1920-1929 birth cohorts & 46.4 & 45.3 & 43.5 & 51.1 & 49.2 & 47.5 \\
\hline 1980-1989 birth cohorts & 45.0 & 42.0 & 42.0 & 49.3 & 46.0 & 45.3 \\
\hline Change & $-1.4^{\dagger}$ & $-3.3^{\dagger}$ & $-1.5^{\dagger}$ & $-1.8^{\dagger}$ & $-3.1^{\dagger}$ & $-2.2^{\dagger}$ \\
\hline $\begin{array}{l}\text { Panel } 4 \text {. If given smoking and weight } \\
\text { composition of: }\end{array}$ & & & & & & \\
\hline 1920-1929 birth cohorts & 46.0 & 45.0 & 43.1 & 51.0 & 48.7 & 47.1 \\
\hline 1980-1989 birth cohorts & 46.0 & 43.4 & 43.5 & 50.3 & 47.3 & 46.3 \\
\hline Change & 0.0 & $-1.5^{\dagger}$ & $0.5^{\dagger}$ & $-0.7^{*}$ & $-1.4^{*}$ & $-0.8^{\dagger}$ \\
\hline
\end{tabular}

Notes: Data sources are 1989 to 2014 National Health Interview Survey with Mortality Linkages, 1999 to 2014 National Health and Nutrition Examination Survey with Mortality Linkages, and 2012 NCHS life tables. FB, foreign-born; USB, U.S.-born. $\uparrow p<0.01 ; * p<0.05$ (tests conducted only for changes).

(1980s) cohorts. We produced these estimates for all 10-year birth cohorts but, for parsimony, only present results for the earliest and latest birth cohorts in Table 3 (see below for more detail about all birth cohorts, which we present in Figure 3).

If given the smoking, weight, and smoking and weight composition of the 1920 to 1929 birth cohorts, the simulated life expectancies for each group are very similar to actual life expectancies (see the first row of results in each panel). Very different patterns emerge when groups are given the smoking and weight composition of the 1980s birth cohorts.

When given the ethnicity/nativity-specific smoking composition of the 1980s birth cohorts, life expectancy significantly increases for all groups except foreignborn Hispanic women (see row three of panel 2). This makes sense given that smoking prevalence declined for all groups. The gain in life expectancy is largest for white men (1.3 years), followed by U.S-born Hispanics ( 0.9 years) and foreign-born Hispanics ( 0.8 years). The relatively large gain for white men seems counterintuitive because smoking prevalence declined more among Hispanics than whites, but it can be explained by whites' higher mortality risk from smoking. Among women, gains are smaller. Foreign-born women make no significant life expectancy gain $(0.1$ year). White women make a very small significant life expectancy gain (0.2 years), as do U.S.-born Hispanic women (0.4 years). 

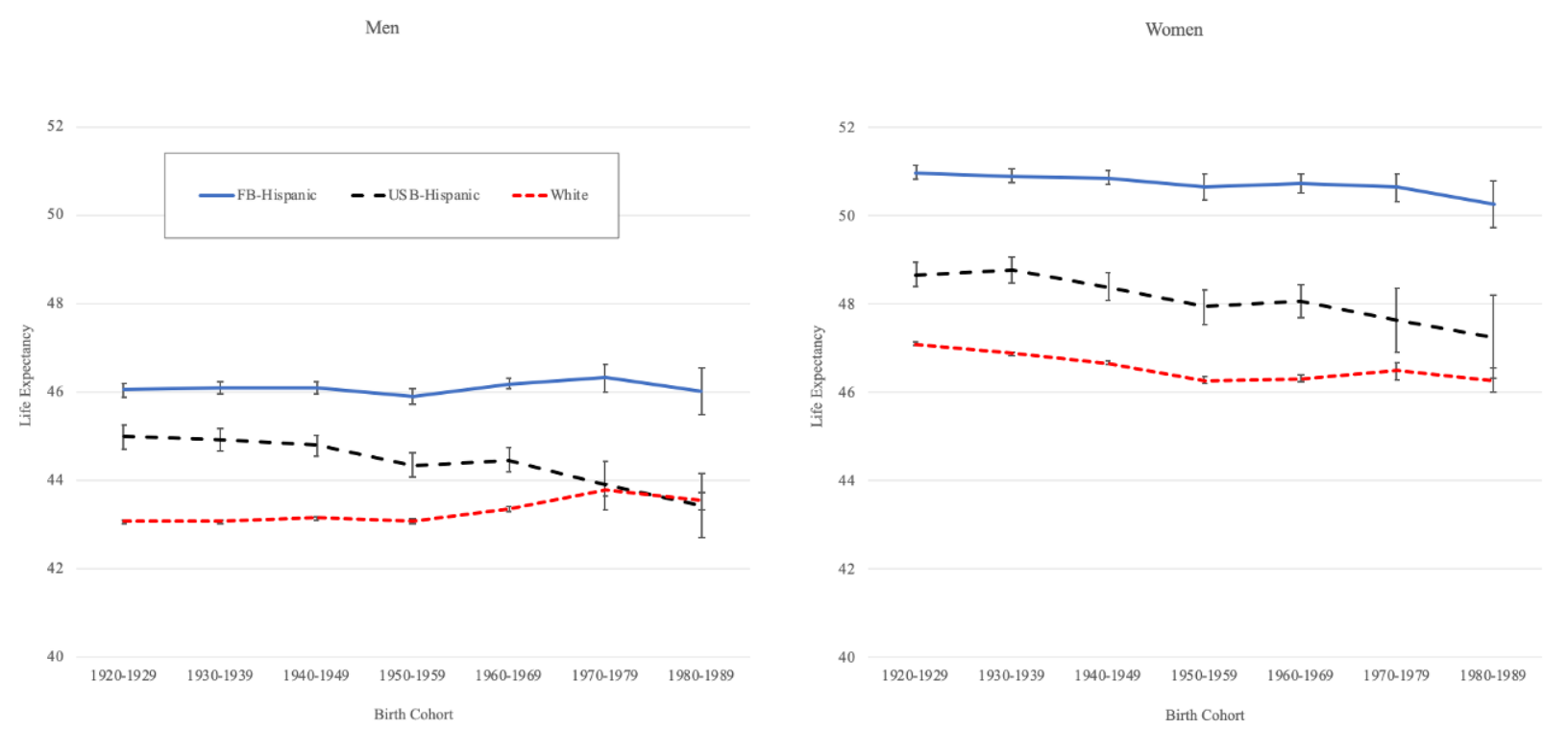

Figure 3: Simulated change in life expectancy at age 35 associated with cohort compositional changes in smoking and weight status at age 25. Source: 1989 to 2014 National Health Interview Survey and 1999 to 2014 National Health and Nutrition Examination Survey. FB, foreign-born; USB, U.S.-born.

When given the weight status composition of the 1980s birth cohorts, life expectancy significantly declines for all groups (see row three of panel 3). Among men, the loss of life among U.S.-born Hispanics is largest, 3.3 years. This is more than double the loss of life estimated for foreign-born Hispanic (1.4 years) and white men (1.5 years). Among women, the loss of life is also largest for U.S.-born Hispanics (3.1 years), but foreign-born Hispanic and white women are also simulated to lose 1.8 and 2.2 years of life, respectively.

Finally, when given both the smoking and weight composition of the 1980s cohorts, the increase associated with smoking and decrease associated with weight cancel each other out for foreign-born Hispanic men. However, U.S.-born Hispanic men lose a year and a half of life, whereas white men gain a half a year. Among women, U.S.-born Hispanics also lose the most years of life (1.4) but foreign-born Hispanic and white women also lose 0.7 and 0.8 years of life, respectively.

To better depict findings in Table 3 and show results for all birth cohorts, Figure 3 elegantly depicts how ethnic/nativity disparities in life expectancy at age 35 are simulated to change as a result of cohort differences in both smoking duration and weight composition. In essence, this figure shows how cohort changes may affect the Hispanic mortality paradox. ${ }^{8}$ Among men (shown in the left half of Figure 3) the life expectancy gap between foreign-born Hispanics and whites is relatively constant over time. It changes from 3.0 to 2.5 years from the earliest to the latest birth cohorts, and this half-year change is not statistically significant. However, Figure 3 also shows that the gap in life expectancy between U.S.-born Hispanic and white men diminishes and completely converges (from 1.9 to -0.1 years). 
A very similar pattern emerges for women, although the disparity between foreign-born Hispanics and whites is larger than what is observed for men (it is consistently a four-year gap or more). Also similar to men, the gap between whites and U.S.-born Hispanics converges, although the one-year difference for women born in the 1980s remains marginally significant $(p=0.06)$.

In summary, results suggest that changes in smoking and weight status are unlikely to change the mortality paradox for foreign-born Hispanics. Yet the paradoxical life expectancy advantage of U.S.-born Hispanics relative to whites appears more tenuous, largely because of the large rise in the obesity prevalence (and especially class 2 obesity) of U.S.-born Hispanics.

\section{Sensitivity Analyses}

We assessed the sensitivity of our results to alternative measures, models, and data sources. First, we used detailed smoking and weight status measures in our main analyses to account for the severity of health conditions, but sample sizes were quite small in some smoking and weight status categories, especially among foreign-born Hispanics. Therefore, we conducted supplemental analyses in which we simply dichotomized smoking and weight status. We classified smoking status as having smoked five or more years as of age 25 and weight status as being obese at age 25 . The effects based on the dichotomized variables tended to be weaker (Table B1 of the online supplement). Nevertheless, the overall impacts of cohort changes in smoking and weight status on the Hispanic paradox were nearly identical to those simulated when health conditions were classified in a more detailed manner (compare Figure B5 of the online supplement with Figure 3): the mortality advantage relative to whites was maintained for foreign-born Hispanics but lost for U.S.-born Hispanics, especially among U.S.-born Hispanic men.

We also investigated the sensitivity of results to whether mortality risks of smoking and weight status are permitted to vary across groups. In our main analyses, we permitted mortality risks to vary because interaction terms between smoking, weight status, and ethnicity/nativity group were significant in the mortality models. However, when we ignored these tests and constrained mortality risks to be the same across ethnicity/nativity groups, the gains in life among foreign-born Hispanics due to smoking were greater, and declines in life for U.S.-born Hispanics due to weight status were less (Table B2 of the online supplement). Constraining mortality risks to be equal also led to the mortality advantage for U.S.-born Hispanics relative to whites being consistently maintained rather than lost (compare Figure B6 of the online supplement with Figure 3). This demonstrates that differential mortality risks partially explain the loss of U.S.-born Hispanics' mortality advantage.

Finally, we assessed the sensitivity of the findings to the data sources used. In our main analyses, we pooled NHANES and NHIS samples, imputed weight history for NHIS respondents using cross-sample multiple imputation, and then dropped the NHANES cases. This greatly expanded the sample size, which permitted us to achieve our primary goal of comparing across ethnic/nativity groups. However, as we explain in Appendix A of the online supplement, this technique rests on the assumption that the data are drawn from the same universe, meaning 
that the two data sources describe the same underlying population (Rendall et al. 2013). Although both NHIS and NHANES are population-representative surveys of the U.S. population, NHANES is different from NHIS because it uses a highly clustered sampling design, relies on face-to-face interviews, and conducts physical examinations. Although our formal tests did not find strong support for violations of the "same-universe" assumption (see Appendix A of the online supplement), we further assessed the robustness of our NHIS-based findings by replicating them using the NHANES data alone. Results are shown in Appendix B (Table B3 and Figure B7) of the online supplement. Regardless of data source, we found that the mortality advantage relative to whites was maintained for foreign-born Hispanics but lost for U.S.-born Hispanics, although the standard errors and confidence intervals of the estimates are much larger for results based on NHANES alone, as would be expected given NHANES's much smaller sample size.

\section{Discussion}

This study sought to build on the small, emerging body of research asking whether the Hispanic paradox can and will endure in the wake of countervailing trends in smoking and obesity. This question has been posed (Goldman 2016; Bostean, Ro, and Fleischer 2017), but to our knowledge, only one previous study has begun to investigate how smoking and obesity both contribute to life expectancy disparities between whites and both foreign-born and U.S.-born Hispanics in the United States (Frisco, Van Hook, and Hummer 2019). Although the previous study advances knowledge about the durability of the Hispanic paradox, it provides a best-case scenario of life expectancy if obesity and smoking were eliminated entirely. This is an important finding for policy interventions that aim to eliminate both of these mortality risks.

Yet our study, which uses an innovative methodological approach to simulate what life expectancy may actually look like given actual cohort changes in smoking and obesity during a 60-year period, provides the best evidence to date about the shape of things to come with respect to the Hispanic paradox. Results for the 1980s birth cohort are especially instructive if the health behaviors of those born in the 1980s have the expected lifelong impacts on morbidity and mortality (Ferraro and Kelley-Moore 2003; Reilley and Kelly 2011; Taghizadeh, Vonk, and Boezen 2016).

Consistent with prior research on the entire U.S. population (Preston et al. 2014), we found that advantages gained by reductions in smoking are roughly balanced out by the losses attributable to the rise in obesity prevalence among whites and foreign-born Hispanics. These offsetting trends are slightly more favorable for the life expectancy of men relative to women. Foreign-born Hispanic men are predicted to have no loss of life, and white men are predicted to gain a half a year of life, whereas foreign-born Hispanic women and white women are predicted to lose 0.7 and 0.8 years of life, respectively. However, for U.S.-born Hispanics, the simulated loss of life is especially large: a net loss of 1.5 years for men and 1.4 years for women. These simulated losses set this group apart.

These findings suggest that for U.S.-born Hispanics, the Hispanic paradox could diminish or even be erased completely by the time that the 1980s birth cohorts grow 
older and replace earlier-born cohorts in the elderly population. Among men, the simulations indicate that the life expectancy of U.S.-born Hispanic and white men will fully converge among the 1970s and 1980s birth cohorts. Women in the 1980s birth cohorts near this convergence, although absolute differences between the U.S.-born Hispanic and white subpopulations of women remain larger than what we observe for men and are at the margins of statistical significance. These findings arise not only because a large and growing share of U.S.-born Hispanics are in the high-risk class 1 and class 2 obese categories, but also because they appear to face particularly high mortality risks among those who are obese. Although we cannot test this, we hypothesize that this elevated risk may be due to the combination of obesity-related comorbidities that may be uncontrolled or detected late due to the lower level of health insurance and health care use of U.S-born Hispanics relative to whites (Escarce and Kapur 2006).

We should note that our analysis only accounts for cohorts born until the end of the 1980s. In the 30 years since these cohorts were born, childhood obesity (and, in turn, continued obesity in adulthood) has become more prevalent (Anderson and Butcher 2006), with even wider disparities in obesity between U.S.-born Hispanic children and whites (Hales et al. 2017). This includes children of immigrants, among whom boys face an especially pronounced obesity risk (Van Hook and Baker 2010; Frisco, Quiros, and Van Hook 2016). Therefore, for today's young people, the elimination of the Hispanic paradox among the U.S.-born may also signal the resumption of a familiar pattern in the United States whereby racial and ethnic minorities live shorter lives than non-Hispanic whites (Cunningham et al. 2017).

For foreign-born Hispanics, however, simulations suggest that the paradox will likely continue and remain quite robust despite cohort shifts in smoking and obesity prevalence. Our analysis extends the research of Fenelon and Blue (2015), who found that reductions in smoking have not eroded the Hispanic paradox, in that we show that only foreign-born Hispanics are poised to retain their paradoxical life expectancy advantage among cohorts born in the 1970s and 1980s. Their continued advantage stems primarily from two factors. First, despite dramatic declines in the prevalence of smoking in the U.S. population, foreign-born Hispanics have maintained their lower smoking prevalence, and in fact, there is evidence that their smoking prevalence has declined even faster than among whites. Second, even though obesity prevalence has increased dramatically in both the United States and in many immigrant-sending countries such as Mexico, the early adult obesity prevalence among foreign-born Hispanics has remained similar to whites for women and a bit lower than whites for men.

The persistence of the paradox for foreign-born Hispanics suggests that their mortality advantage may not be tied to a particular health condition or behavior, such as smoking or obesity. Rather, the paradox among immigrants seems to persist across birth cohorts despite national shifts in the prevalence or risk of smoking and obesity, and in the face of a host of other negative factors that would ordinarily place a population at great risk of reduced life expectancy (e.g., low socioeconomic status, limited access to health care, hazardous work conditions, and undocumented status) (Turra and Goldman 2007; Escarce and Kapur 2006; Hall and Greenman 2015; Hamilton, Hale, and Savinar 2019). Therefore, our results add to evidence that the 
Hispanic immigrant paradox in life expectancy stems from upstream mechanisms related to the immigration process and immigrant status. Immigration-related selection mechanisms may sort would-be immigrants on the capacity to migrate and work, which indirectly also positively selects them on health and health risks (Riosmena, Wong, and Palloni 2013; Riosmena, Kuhn, and Jochem 2017; Van Hook et al. 2012). Additionally, mechanisms related to childhood cultural contexts outside the United States may protect immigrants from a host of health risks that come with the adoption of an American-style consumer lifestyle (Van Hook et al. 2018). For example, evidence suggests that Mexican immigrants retain customary Mexican food consumption and avoid U.S. foods regardless of their socioeconomic status (Frisco, Adler, and Van Hook 2019).

Nonetheless, our study has limitations. First, estimates of Hispanic mortality risk based on linked mortality records, which we use here, have been found to depend on the linkage algorithms used, particularly when estimating mortality earlier than age 65 (Lariscy 2011). This is presumably because Hispanics are less likely to report a Social Security number in the NHIS. It is therefore possible that we have underestimated Hispanic mortality risks, particularly among foreign-born Hispanics, many of whom do not have Social Security numbers. Nevertheless, linkage bias seems less likely to impact findings about how smoking and weight status trends have reduced U.S.-born Hispanics' life expectancy advantage. U.S.born Hispanics are likely to have Social Security numbers, and we have no evidence that linkage bias would differ by smoking or weight status. Moreover, we obtain very similar results when we estimate life expectancy at age 65 (an age group found to have less linkage bias) and when we estimate life expectancy at age 35 .

A second limitation is that the negative consequences of obesity for longevity accumulate with age, as do the consequences of smoking. Currently our simulations are based on self-reported estimates of height and weight at the age of 25 that likely contain some error and do not fully tap the risks of early adult obesity for youngest cohorts, who are actually more likely than older cohorts to be obese well before the age of 25. Similarly, our current conceptualization of smoking is quite blunt and does not disaggregate smoking cessation from current smoking or heavy smokers from light and moderate smokers. These are all important considerations for the likelihood of smoking-attributable mortality. These limitations, though, render results from our simulations as being very conservative estimates of how obesity and smoking changes over time may influence total and healthy life expectancy. Additional limitations include our inability to speak to a few important and pressing health problems that are also changing mortality risks. This includes recent declines in life expectancy in the United States (Xu et al. 2020); increasing rates of "deaths of despair" from suicide, drug overdoses, and alcohol abuse (Monnat and Brown 2017); the recent COVID-19 epidemic; and the unfortunate likelihood that smoking trends may change as e-cigarettes and vaping encourage more young people in the United States to smoke (Miech et al. 2017). U.S.-born Hispanic youth may be particularly susceptible to these risks, so these are fruitful lines of investigation for future research.

Results to date, though, have important implications. Although it is encouraging that reductions in smoking could have positive implications for life expectancy, it 
is discouraging to see how obesity may erode life expectancy gains and may lead to the reduction or even the elimination of the health protections that U.S.-born Hispanics have experienced over the last several decades.

\section{Notes}

1 We display the share that smoked less than five years, five to nine years, and 10 or more years by age 25 in Figure B1 of the online supplement. These more detailed breakdowns suggest continuity in the share of each cohort that smoked for only brief periods of time as adolescents or young adults. However, the share that smoked for longer durationsa group that is at greater risk of becoming lifelong smokers-declined considerably. Although cohort declines begin earlier for men, among both men and women, there is an abrupt drop-off in longer-term smoking observed between the 1960s and 1970s birth cohorts, which corresponds to the release of the 1964 U.S. Surgeon General's report on smoking.

2 NCHS does not publish Hispanic life tables by nativity, so we estimate $q_{x}$ 's for foreignborn and U.S.-born Hispanic life tables such that (1) they correspond with the relative mortality risks observed in the NHIS-linked mortality data and (2) their weighted average equals the $q_{x}$ 's in the 2012 Hispanic life tables published by NCHS.

3 https://www.cdc.gov/healthyweight/assessing/bmi/adult_bmi/index.html.

4 In models estimated for all ethnicity/nativity groups combined, interactions between ethnicity/nativity and smoking and obesity were statistically significant, supporting our decision to stratify the models by group.

5 We tested the proportional hazard assumption by testing interactions between weight status and age, but these were not significant. On the basis of these tests, we opted for simpler models that assume that the relative hazard of dying for each weight and smoking category is constant across all age groups.

6 For example, the $q_{x, w}$ terms for normal weight foreign-born Hispanic women in Equation (1) were calculated as $q_{x, w 1, \mathrm{FB} \text { Hisp female }}=q_{x, \mathrm{NCHS} \text {,FB Hisp female }} \cdot H_{w 1 \text {,FB Hisp female, }}$ where $\mathrm{H}$ is the hazard ratio.

7 The statistical significance of these contrasts was confirmed by examining the significance levels of the appropriate interaction terms in the pooled model.

8 Figures B3 and B4, respectively, of the online supplement show changes in ethnic/nativity disparities across cohorts when cohort smoking composition only and weight composition only are used as inputs in simulations.

\section{References}

Adler, Nancy E., and Katherine Newman. 2002. Socioeconomic Disparities in Health: Pathways and Policies. Health Affairs 21(2):60-76. https://doi.org/10.1377/hlthaff . 21.2.60.

Akresh, Ilana Redstone. 2008. “Overweight and Obesity among Foreign-Born and U.S.-Born Hispanics." Biodemography and Social Biology 54(2):183-99. https://doi .org/10.1080/ 19485565.2008 .9989141$.

Alley, Dawn E., Jeffrey Metter, Michael E. Griswold, Tamara B. Harris, Eleanor M. Simonsick, Dan L. Longo, and Luigi Ferrucci. 2010. "Changes in Weight at the End of Life: Charac- 
terizing Weight Loss by Time to Death in a Cohort Study of Older Men." American Journal of Epidemiology 172(5):558-65. https ://doi .org/10.1093/aje/kwq168.

Anderson, Patricia M., and Kristin E. Butcher. 2006. "Childhood Obesity: Trends and Potential Causes." Future of Children 16(1):19-45. https ://doi .org/10.1353/foc. 2006. 0001.

Antecol, Heather, and Kelly Bedard. 2006. "Unhealthy Assimilation: Why do Immigrants Converge to American Health Status Levels?" Demography 43(2):337-60. https ://doi . org/10.1353/dem.2006.0011.

Baker, Elizabeth, Michael Rendall, and Margaret Weden. 2015. "Epidemiological Paradox or Immigrant Vulnerability? Obesity among Young Children of Immigrants." Demography 52(4):1295-320. https://doi .org/10.1007/s13524-015-0404-3.

Barcenas, Carlos H., Anna V. Wilkinson, Sara S. Strom, Yumei Cao, Katherine C. Saunders, Somdat Mahabir, María A. Hernández-Valero, Michele R. Forman, Margaret R. Spitz, and Melissa L. Bondy. 2007. "Birthplace, Years of Residence in the United States, and Obesity among Mexican-American Adults." Obesity 15(4):1043-52. https://doi .org/10.1038/ oby .2007 .537$.

Blewett, Lynn A., Julia A. Rivera Drew, Miriam L. King, and Kari C. W. Williams. 2019. IPUMS Health Surveys: National Health Interview Survey, Version 6.4 [dataset]. Minneapolis, MN: IPUMS. https://doi.org/10.18128/D070.V6.4.

Bostean, Georgiana, Annie Ro, and Nancy L. Fleischer. 2017. "Smoking Trends among U.S. Latinos, 1998-2013: The Impact of Immigrant Arrival Cohort." International Journal of Environmental Research and Public Health 14(3):255. https://doi.org/10.3390/ ijerph14030255.

Centers for Disease Control and Prevention. 2016a. Trends in Current Cigarette Smoking among High School Students and Adults, United States. Atlanta, GA: Office on Smoking and Health, National Center for Chronic Disease Prevention and Health Promotion.

Centers for Disease Control and Prevention. 2016b. Current Cigarette Smoking among Adults in the United States. Atlanta, GA: National Center for Chronic Disease Prevention and Health Promotion Office on Smoking and Health.

Clarke, Philippa J., Patrick M. O’Malley, John E. Schulenberg, and Lloyd D. Johnston. 2010. "Midlife Health and Socioeconomic Consequences of Persistent Overweight across Early Adulthood: Findings from a National Survey of American Adults (1986-2008)." American Journal of Epidemiology 172(5):540-48. https : //doi .org/10.1093/aje/kwq156.

Cunningham, Timothy J., Janet B. Croft, Yong Liu, Hua Lu, Paul I. Eke, and Wayne H. Giles. 2017. “Vital Signs: Racial Disparities in Age-Specific Mortality among Blacks or African Americans - United States, 1999-2015." Morbidity and Mortality Weekly Report 66(17):444-56. http://doi.org/10.15585/mmwr.mm6617e1.

Dietz, William H. 2017. "Obesity and Excessive Weight Gain in Young Adults: New Targets for Prevention." Journal of the American Medical Association 318(3):241-42. https://doi . org/10.1001/jama.2017.6119.

Escarce, José J., and Kanika Kapur. 2006. “Access to and Quality of Health Care." Pp. 410-46 in Hispanics and the Future of America, edited by Marta Tienda and Faith Mitchell. Washington, DC: National Academies Press.

Fenelon, Andrew. 2013. "Revisiting the Hispanic Mortality Advantage in the United States: The Role of Smoking." Social Science and Medicine 82:1-9. https://doi .org/10.1016/j . socscimed.2012.12.028. 
Fenelon, Andrew, and Laura Blue. 2015. "Widening Life Expectancy Advantage of Hispanics in the United States: 1990-2010." Journal of Immigrant and Minority Health 17(4):1130-37. https://doi .org/10.1007/s10903-014-0043-6.

Ferraro, Kenneth F., and Jessica A. Kelley-Moore. 2003. "Cumulative Disadvantage and Health: Long-Term Consequences." American Sociological Review 68(5):707-29. https: //doi .org/10.2307/1519759.

Flanders, W. Dana, Cathy A. Lally, Bao-Ping Zhu, S. Jane Henley, and Michael J. Thun. 2003. "Lung Cancer Mortality in Relation to Age, Duration of Smoking, and Daily Cigarette Consumption: Results from Cancer Prevention Study II." Cancer Research 63(19):6556-62.

Freedman, David S., Laura Kettel Khan, William H. Dietz, Sathanur R. Srinivasan, and Gerald S. Berenson. 2001. "Relationship of Childhood Obesity to Coronary Heart Disease Risk Factors in Adulthood: The Bogalusa Heart Study." Pediatrics 108(3):712-18. https : //doi.org/10.1542/peds.108.3.712.

Freedman, D. Michal, Alice J. Sigurdson, Preetha Rajaraman, Michele M. Doody, Martha S. Linet, and Elaine Ron. 2006. "The Mortality Risk of Smoking and Obesity Combined." American Journal of Preventive Medicine 31(5):355-62. https : //doi .org/10.1016/ j . amepre.2006.07.022.

Frisco, Michelle L., Jennifer Van Hook, and Robert A. Hummer. 2019. “Would the Elimination of Obesity and Smoking Reduce U.S. Racial/Ethnic/Nativity Disparities in Total and Healthy Life Expectancy?" SSM - Population Health 7:100374. https://doi.org/10. 1016/j.ssmph.2019.100374.

Frisco, Michelle L., Susana Quiros, and Jennifer Van Hook. 2016. "One Size May Not Fit All: How Obesity among Mexican-Origin Youth Varies by Generation, Gender, and Age." Demography 53(6):2031-43. https : //doi .org/10.1007/s13524-016-0525-3.

Frisco, Michelle L., Gary Adler, and Jennifer Van Hook. 2019. “Standing Out or Fitting In? How Generational Status Produces Contradictions in Food Consumption Practices of Higher SES Mexican-Origin Adults." Paper presented at the Annual Meeting of the American Sociological Association, August 9-13, New York, NY.

Fryar, Cheryl D., Margaret D. Carroll, and Cynthia L. Ogden. 2016. “Prevalence of Overweight, Obesity, and Extreme Obesity among Adults Aged 20 and Over: United States, 1960-1962 through 2013-2014." Health E-Stats. Atlanta, GA: National Center for Health Statistics. https://www.cdc.gov/nchs/data/hestat/obesity_adult_13_14/obesity_ adult_13_14.pdf.

Frytak Jennifer R., Carolyn R. Harley, and Michael D. Finch. 2003. “Socioeconomic Status and Health over the Life Course: Capital as a Unifying Concept." Pp. 623-43 in Handbook of the Life Course, edited by Jeylan T. Mortimer and Michael J. Shanahan. Boston, MA: Springer.

Gaddey, Heidi L., and Kathryn Holder. 2014. "Unintentional Weight Loss in Older Adults." American Family Physician 89(9):718-22.

Goldman, Noreen. 2016. "Will the Latino Mortality Advantage Endure?" Research on Aging 38(3):263-82. https ://doi.org/10.1177/0164027515620242.

Hales, Craig M., Margaret D. Carroll, Cheryl D. Fryar, and Cynthia L. Ogden. 2017. "Prevalence of Obesity among Adults and Youth: United States, 2015-2016." NCHS Data Brief (288):1-7.

Hales, Craig M., Margaret D. Carroll, Cheryl D. Fryar, and Cynthia L. Ogden. 2020. “Prevalence of Obesity and Severe Obesity among Adults: United States, 2017-2018." NCHS Data Brief (360):1-8. 
Hall, Matthew, and Greenman, Emily. 2015. "The Occupational Cost of Being Illegal in the United States: Legal Status, Job Hazards, and Compensating Differentials." International Migration Review 49(2):406-42. https : //doi .org/10.1111/imre.12090.

Hamilton, Erin R., Hale, Jo Mhairi, and Robin Savinar. 2019. “Immigrant Legal Status and Health: Legal Status Disparities in Chronic Conditions and Musculoskeletal Pain among Mexican-Born Farm Workers in the United States." Demography 56(1):1-24. https : //doi .org/10.1007/s13524-018-0746-8.

Hamilton, Tod G., Tia Palermo, and Tiffany L. Green. 2015. “Health Assimilation among Hispanic Immigrants in the United States: The Impact of Ignoring Arrival-Cohort Effects." Journal of Health and Social Behavior 56(4):460-77. https://doi .org/10.1177/ 0022146515611179.

Hayward, Mark D., and Bridget K. Gorman. 2004. "The Long Arm of Childhood: The Influence of Early Life Social Conditions on Men's Mortality." Demography 41(1):87-107. https://doi.org/10.1353/dem.2004.0005.

Hummer, Robert A., Daniel A. Powers, Starling G. Pullum, Ginger L. Gossman, and W. Parker Frisbie. 2007. "Paradox Found (Again): Infant Mortality among the MexicanOrigin Populations in the United States." Demography 44(3):441-57. https : //doi .org/ 10.1353/dem.2007.0028.

Hummer, Robert A., Richard G. Rogers, Charles B. Nam, and Felicia B. LeClere. 1999. "Race/Ethnicity, Nativity and U.S. Adult Mortality." Social Science Quarterly 80(1):136-53.

Hummer, Robert A., Richard G. Rogers, Sarit H. Amir, Douglas Forbes, and W. Parker Frisbie. 2000. "Adult Mortality Differentials among Hispanic Subgroups and Non-Hispanic Whites." Social Science Quarterly 81(1):459-76.

Kaplan, Mark S., Nathalie Huguet, Jason T. Newsom, and Bentson H. McFarland. 2004. "The Association between Length of Residence and Obesity among Hispanic Immigrants." American Journal of Preventive Medicine 27(4):323-26. https : //doi . org/10 . 1016/ j.amepre.2004.07.005.

Kim, Miji, Junghoon Kim, and Chang Won Won. 2018. “Association between Involuntary Weight Loss with Low Muscle Mass and Health-Related Quality of Life in CommunityDwelling Older Adults: Nationwide Surveys (KNHANES 2008-2011)." Experimental Gerontology 106:39-45. https://doi .org/10.1016/j . exger.2018.02.027.

Kranjac, Ashely Wendell, and Robert L. Wagmiller. 2019. "Decomposing Trends in Child Obesity." Population Research and Policy Review 39:375-88. https ://doi .org/10.1007/ s11113-019-09544-z.

Lariscy, Joseph T. “Differential Record Linkage by Hispanic Ethnicity and Age in Linked Mortality Studies: Implications for the Epidemological Paradox." Journal of Aging and Health 23(8):1264-84. https : //doi .org/10.1177/0898264311421369.

Lariscy, Joseph T., Robert A. Hummer, and Mark D. Hayward. 2015. “Hispanic Older Adult Mortality in the United States: New Estimates and an Assessment of Factors Shaping the Hispanic Paradox." Demography 52(1):1-14. https://doi .org/10.1007/ s13524-014-0357-y.

Markides, Kyriakos S., and Jeannine Coreil. 1986. "The Health of Hispanics in the Southwestern United States: An Epidemiologic Paradox." Public Health Reports 101(3):253-65.

McTigue, Kathleen M., Joanne M. Garrett, and Barry M. Popkin. 2002. “The Natural History of the Development of Obesity in a Cohort of Young U.S. Adults between 1981 and 1998." Annals of Internal Medicine 136(12):857-64. https : //doi .org/10.7326/ 0003-4819-136-12-200206180-00006. 
Miech, Richard, Megan E. Patrick, Patrick M. O'Malley, and Lloyd D. Johnston. 2017. “ECigarette Use as a Predictor of Cigarette Smoking: Results from a 1-Year Follow-Up of a National Sample of 12th Grade Students. Tobacco Control 26(e2):e106-11. https : //doi.org/10.1136/tobaccocontrol-2016-053291.

Monnat, Shannon M., and David L. Brown. 2017. "More than a Rural Revolt: Landscapes of Despair and the 2016 Election." Journal of Rural Studies 55:227-36. https : //doi . org/10 . 1016/j.jrurstud.2017.08.010.

Morales, Leo S., Marielena Lara, Raynard S. Kington, Robert O. Valdez, and José J. Escarce. 2002. "Socioeconomic, Cultural, and Behavioral Factors Affecting Hispanic Health Outcomes." Journal of Health Care for the Poor and Underserved 13(4):477-503. https: //doi.org/10.1353/hpu.2010.0630.

Peeters, Anna, Jan J. Barendregt, Frans Willekens, Johan P. Mackenbach, Abdullah Al Mamun, and Luc Bonneux, and for the Netherlands Epidemiology and Demography Compression of Morbidity Research Group (NEDCOM). 2003. "Obesity in Adulthood and Its Consequences for Life Expectancy: A Life-Table Analysis." Annals of Internal Medicine 138(1):24-32. https://doi.org/10.7326/0003-4819-138-1-200301070-00008.

Preston, Samuel H., and Haidong Wang. 2006. "Sex Mortality Differences in the United States: The Role of Cohort Smoking Patterns." Demography 43(4):631-46. https : //doi . org/10.1353/dem.2006.0037.

Preston, Sameul H., Andrew Stokes, Neil K. Mehta, and Bochen Cao. 2014. "Projecting the Effect of Changes in Smoking and Obesity on Future Life Expectancy in the United States." Demography 51(1):27-49. https ://doi .org/10.1007/s13524-013-0246-9.

Reilly, J. J., and J. Kelly. 2011. “Long-Term Impact of Overweight and Obesity in Childhood and Adolescence on Morbidity and Premature Mortality in Adulthood: Systematic Review." International Journal of Obesity 35(7):891-98. https://doi .org/10.1038/ijo. 2010.222.

Reither, Erin N., Robert M. Hauser, and Yang Yang. 2009. “Do Birth Cohorts Matter? AgePeriod-Cohort Analyses of the Obesity Epidemic in the United States." Social Science and Medicine 69(10):1439-48. https://doi .org/10.1016/j . socscimed . 2009 .08.040.

Reither, Erin N., S. Jay Olshansky, and Yang Yang. 2011. "New Forecasting Methodology Indicates More Disease and Earlier Mortality Ahead for Today's Younger Americans." Health Affairs 30(8):1562-68. https://doi .org/10.1377/hlthaff.2011.0092.

Rendall, Michael S., Bonnie Ghosh-Dastidar, Margaret M. Weden, Elizabeth H. Baker, and Zafar Nazarov. 2013. "Multiple Imputation for Combined-Survey Estimation with Incomplete Regressors in One but Not Both Surveys." Sociological Methods E Research 42(4):483-530. https://doi.org/10.1177/0049124113502947.

Riosmena, Fernando, Randall Kuhn, and Warren C. Jochem. 2017. “Explaining the Immigrant Health Advantage: Self-Selection and Protection in Health-Related Factors among Five Major National-Origin Immigrant Groups in the United States." Demography 54(1):175200. https://doi.org/10.1007/s13524-016-0542-2.

Riosmena, Fernando, Rebeca Wong, and Alberto Palloni. 2013. "Migration, Selection, Protection, and Acculturation in Health: A Binational Perspective on Older Adults." Demography 50(3):1039-64. https ://doi .org/10.1007/s13524-012-0178-9.

Siahpush, M., G. K. Singh, P. R. Jones, and L. R. Timsina. 2010. “Racial/Ethnic and Socioeconomic Variations in Duration of Smoking: Results from 2003, 2006 and 2007 Tobacco Use Supplement of the Current Population Survey." Journal of Public Health 32(2):210-18. https://doi.org/10.1093/pubmed/fdp104. 
Stewart, Susan T., David M. Cutler, and Allison B. Rosen. 2009. "Forecasting the Effects of Obesity and Smoking on U.S. Life Expectancy." New England Journal of Medicine 361(23):2252-60. https://doi .org/10.1056/NEJMsa0900459.

Taghizadeh, Niloofar, Judith M. Vonk, and H. Marike Boezen. 2016. "Lifetime Smoking History and Cause-Specific Mortality in a Cohort Study with 43 Years of Follow-Up." PLoS One 11(4):e0153310. https : //doi .org/10.1371/journal . pone. 0153310.

Trinidad, Dennis R., Eliseo J. Pérez-Stable, Sherry L. Emery, Martha M. White, Rachel A. Grana, and Karen S. Messer. 2009. "Intermittent and Light Daily Smoking across Racial/Ethnic Groups in the United States." Nicotine and Tobacco Research 11(2):203-10. https://doi .org/10.1093/ntr/ntn018.

Turra, Cassio M., and Irma T. Elo. 2008. "The Impact of Salmon Bias on the Hispanic Mortality Advantage: New Evidence from Social Security Data." Population Research and Policy Review 27(5):515-30. https ://doi .org/10.1007/s11113-008-9087-4.

Turra, Cassio M., and Noreen Goldman. 2007. "Socioeconomic Differences in Mortality among US Adults: Insights into the Hispanic Paradox." Journals of Gerontology Series B: Psychological Sciences and Social Sciences 62(3):S184-92. https://doi.org/10.1093/ geronb/62.3.S184.

U.S. Department of Health and Human Services. 2014. The Health Consequences of Smoking50 Years of Progress: A Report of the Surgeon General. Atlanta, GA: U.S. Department of Health and Human Services, Centers for Disease Control and Prevention, National Center for Chronic Disease Prevention and Health Promotion, Office on Smoking and Health.

Van Baak, Marleen A., and Edwin C. M. Mariman. 2019. “Mechanisms of Weight Regain after Weight Loss — the Role of Adipose Tissue." Nature Reviews Endocrinology 15(5):274-87. https://doi.org/10.1038/s41574-018-0148-4.

Van Hook, Jennifer, and Elizabeth Baker. 2010. “Big Boys, Little Girls: Gender, Acculturation, and Weight among Young Children of Immigrants." Journal of Health and Social Behavior 51(2):200-14. https ://doi.org/10.1177/0022146510372347.

Van Hook, Jennifer, James D. Bachmeier, Donna L. Coffman, and Ofer Harel. 2015. "Can We Spin Straw into Gold? An Evaluation of Immigrant Legal Status Imputation Approaches." Demography 52(1):329-54. https : //doi .org/10 .1007/s13524-014-0358-x.

Van Hook, Jennifer, Elizabeth Baker, Claire E. Altman, and Michelle L. Frisco. 2012. "Canaries in a Coalmine: Immigration and Obesity among Mexican-Origin Children." Social Science and Medicine 74(2):125-34. https : //doi .org/10.1016/j . socscimed.2011.10.007.

Van Hook, Jennifer, Susana Quirós, Molly Dondero, and Claire E. Altman. 2018. "Healthy Eating among Mexican Immigrants: Migration in Childhood and Time in the U.S." Journal of Health and Social Behavior 59(3):391-410. https : //doi .org/10.1177/0022146518788869.

Weiss, Edward C., Deborah A. Galuska, Laura Kettel Khan, Cathleen Gillespie, and Mary K. Serdula. 2007. "Weight Regain in U.S. Adults Who Experienced Substantial Weight Loss, 1999-2002." American Journal of Preventive Medicine 33(1):34-40. https : //doi .org/ 10.1016/j . amepre.2007.02.040.

Xu, Jianquan, Sherry L. Murphy, Kenneth D. Kochanek, and Elizabeth Arias. 2020. Mortality in the United States, 2018. NCHS Data Brief (355):1-8.

Zhang, Hong, and Rosa Rodriguez-Monguio. 2012. "Racial Disparities in the Risk of Developing Obesity-Related Diseases: A Cross-Sectional Study." Ethnicity and Disease 22(3):308-16. 
Acknowledgments: We are grateful to Virginia Chang for helpful comments in her role as a discussant of this article at the 2019 meeting of the Population Association of America. We also acknowledge assistance provided by the Population Research Institute at Penn State University, which is supported by an infrastructure grant from the Eunice Kennedy Shriver National Institute of Child Health and Human Development (P2CHD041025).

Jennifer Van Hook: Department of Sociology, Penn State University. E-mail: jxv21@psu.edu.

Michelle L. Frisco: Department of Sociology, Penn State University. E-mail: mlf112@psu.edu.

Carlyn E. Graham: Department of Sociology, Penn State University. E-mail: ceg248@psu.edu. 